\title{
RESEARCH
}

Open Access

\section{HIV knowledge and risk behaviors among drug users in three Vietnamese mountainous provinces}

Tam Minh Thi Nguyen ${ }^{1}$, Bach Xuan Tran ${ }^{2,3,4^{*}}$ D, Mercedes Fleming ${ }^{5}$, Manh Duc Pham ${ }^{1}$, Long Thanh Nguyen ${ }^{1}$, Anh Lan Thi Nguyen ${ }^{6}$, Huong Thi Le², Thang Huu Nguyen², Van Hai Hoang ${ }^{2}$, Xuan Thanh Thi Le², Quan Hoang Vuong ${ }^{7,8}$, Manh Tung Ho ${ }^{9}$, Van Nhue Dam ${ }^{10}$, Thu Trang Vuong ${ }^{11}$, Vu Nguyen ${ }^{12}$, Huong Lan Thi Nguyen ${ }^{13}$, Huyen Phuc Do ${ }^{14}$, Phuong Linh Doan ${ }^{14}$, Hai Hong Nguyen ${ }^{14}$, Carl A. Latkin ${ }^{3}$, Cyrus S. H. Ho ${ }^{15}$ and Roger C. M. Ho ${ }^{16,17}$

\begin{abstract}
Background: Globally, people who inject drugs are highly vulnerable to HIV transmission. Methadone maintenance treatment (MMT) programs are one of the most cost-effective mechanisms to substitute opioid use and improve the quality of life of patients. Since the coverage of MMT is still limited and even for those patients who are treated, improving their knowledge on HIV and maintaining healthy behaviors are key to maximizing the outcomes of HIV harm reduction programs. This study examined the knowledge on HIV, perceived risk and HIV testing among drug users accessing methadone maintenance services in three Vietnamese mountainous areas.
\end{abstract}

Methods: A cross-sectional study of 300 people enrolling for MMT services in three provinces in Vietnam was conducted. The factors associated with the knowledge, attitudes, and practices of respondents about HIV/AIDS were exploited using multivariable logistic model.

Results: Of the 300-people surveyed, 99\% knew of HIV and 60.6\% were identified as having good knowledge. While $75.2 \%$ identified that injecting drugs was a risk factor for HIV, 52.2\% thought they were not at risk of HIV mainly as they did not share needles. $92.6 \%$ had undergone HIV testing with $17.4 \%$ being positive, a number which was significantly lower than Vietnam's national average for people who inject drugs. Age, ethnicity and education were associated with knowledge of HIV while ART treatment was linked to self-assessed HIV status.

Conclusions: This study sheds new light on the knowledge attitudes and practices of people who inject drugs, particularly males in mountainous areas of Vietnam regarding HIV prevention. Overall, knowledge was good with most conducting safe practices towards transmission. Enhanced education and targeting of minority groups could help in increasing the numbers receiving MMT and HIV services.

Keywords: Methadone maintenance, HIV, Mountainous Vietnam, Knowledge, Attitudes, Practices

\footnotetext{
* Correspondence: bach.jhu@gmail.com

${ }^{2}$ Institute for Preventive Medicine and Public Health, Hanoi Medical

University, Hanoi, Vietnam

${ }^{3}$ Bloomberg School of Public Health, Johns Hopkins University, Baltimore,

MD, USA

Full list of author information is available at the end of the article
}

(c) The Author(s). 2019 Open Access This article is distributed under the terms of the Creative Commons Attribution 4.0 International License (http://creativecommons.org/licenses/by/4.0/), which permits unrestricted use, distribution, and reproduction in any medium, provided you give appropriate credit to the original author(s) and the source, provide a link to the Creative Commons license, and indicate if changes were made. The Creative Commons Public Domain Dedication waiver (http://creativecommons.org/publicdomain/zero/1.0/) applies to the data made available in this article, unless otherwise stated. 


\section{Background}

Globally, people who inject drugs (PWID) remain a highly vulnerable group when it comes to HIV infections [1]. Of the estimated 13-16 million people living worldwide who inject drugs, it is though that up to 1.7 million are living with HIV [2, 3]. Injecting drug practices account for up to $10 \%$ of new HIV infections and when Africa is excluded, 30\% [4, 5]. Drug injection as a risk factor in contracting HIV was implicated in causing 2.0 million Disability-Adjusted-Life Years (DALYs) in 2010 [3]. As well as this, HIV is the major cause of morbidity and mortality among PWID [6]. This demonstrates the significant economic burden that HIV infections have especially when in addition to the drug use burden, which in the United States in 2007 was approximately $\$ 193$ billion [7]. The burden of HIV infections among PWIDs is not solely economic however. The individual and social impact of both is significant. As both groups are typically exposed to stigma and ostracized from communities, obtaining work and playing a "normal" role in society can be difficult. Being both a PWID and HIV positive can potentiate these effects. This can have substantial consequences for patients' mental health.

One of the most cost effective health care interventions for PWID is the introduction of methadone maintenance treatments (MMT) to assist people in withdrawing from using opioid drugs $[8,9]$. As well as being cost-effective, MMT has been shown in several studies in Malaysia, Taiwan and China to be efficacious in reducing the needs of PWID to use other drugs and in the improvement of socioeconomic factors for these people [10-12]. The positive effects of MMT have been seen when applied to HIV-positive PWID as well. Globally, MMT has been demonstrated to have positive effects on HIV patients' treatment and risk behavior patterns as well as in the prevention of new HIV infections [13-15]. As reviewed by Karki et al. patients who initiate MMT programs globally have been shown to have reduced risk of HIV, improved HIV prevention behaviors and are more likely to engage with HIV testing [14].

Since 2008, Vietnam has introduced, and rapidly developed, an MMT plan to reduce the number of PWID within the country and in turn, to help to decrease HIV transmission [16]. Currently there are 251 MMT centers across Vietnam catering to about 46,000 patients [17]. As well as this, HIV treatment services have been rapidly improved to include 364 centers [18]. In Vietnam, currently about 260,000 people have been diagnosed with HIV with rates remaining stable over the last 3 years [19]. In some provinces up to $30 \%$ of these HIV patients are PWID [20], highlighting the impact that intravenous drug use has on HIV transmission. In previous studies, changes to drug use behavior due to MMT in Vietnam have been associated with reduced risk behaviors and improved quality of life among patients [21]. MMT services are now seen as a key mechanism for accessing the hidden drug using population in Vietnam as funding for peer-to-peer outreach declines $[22,23]$. In addition, by accessing MMT programs, patients can be further referred to other HIV/ AIDS or general health services in a timely manner. However, the current coverage of MMT services is still limited, especially in mountainous areas. In addition, even for those patients who were treated with the methadone medication, improving their knowledge of HIV/AIDS and risk behaviors is key to maximizing the impact of harm reduction programs.

Expanding MMT services as well as other harm reduction activities in mountainous areas, has been very challenging given the geographical barriers, patients' mobility and there being higher rates of health problems and risk behaviors. However, data regarding the characteristics of the target population accessing MMT in this setting is very limited. This study examined the knowledge on HIV, perceived risk and HIV testing among drug users accessing methadone maintenance services in three Vietnamese mountainous areas. The findings of this study may inform the expansion strategies of MMT as well as assist in designing other necessary harm reduction interventions for drug users in this setting.

\section{Methods}

\section{Study setting}

A cross-sectional study was conducted in December 2014 in three mountainous provinces Dien Bien, Lai Chau and Yen Bai. Clinics providing HIV/AIDS services which met the following criteria were chosen: 1) Having integrated MMT services; 2) being in an urban or rural area; and 3) providing service at the provincial and district levels of the Vietnamese healthcare system. Patients who registered at Provincial AIDS Centers in Dien Bien, Lai Chau and Yen Bai City; and District Health Centers in Thanh Xuong, Phong Tho and Nghia Lo District for services such as HIV testing or treatment were interviewed. While patients had availed of HIV/AIDS services this did not necessarily mean they needed HIV treatment or were HIV positive.

We invited patients who fulfilled the eligibility criteria of: i) using MMT services at one of the chosen clinics; ii) being 18 years old or older; iii) being able to answer the structured questionnaire. We used a consecutive sampling approach to recruit participants. We interviewed 300 drug users, all of whom met the criteria and agreed to join in the study. All (100\%) of enrolled participants were male, due to the fact that our selected clinics consisted of only male patients. 


\section{Measures and instruments}

Face-to-face interviews of 15-min duration using structured questionnaires were conducted to collect data from the participants. Data collectors were post-graduate students from Hanoi Medical University who were trained in conducting community survey prior to this study. The questionnaire was piloted in $10 \mathrm{MMT}$ patients, revised based on their feedbacks and implemented widely after that.

We asked drug users about their knowledge, attitudes and practices of HIV prevention and treatment. The knowledge surveyed included: 1) HIV/AIDS transmission; 2) susceptibility to HIV infection; and 3) HIV prevention according to 5 questions set by the Vietnam Ministry of Health in 2007. The respondents were asked to answer 5 True/False questions. If drug users answered all questions correctly, they had good knowledge and if they answered incorrectly, they had poor knowledge. The internal consistency was low with the Cronbachs' alpha $=0.5074$.

The attitudes surveyed included: 1) self-assessed HIV status (meaning the HIV status participants felt they were - HIV positive or negative, or as having their HIV viral load suppressed - but without confirmatory medical testing); 2) reasons for risk of HIV/AIDS infection; and 3) reasons for no risk of HIV/AIDS infection. The practices surveyed included: 1) using HIV testing and counselling services before beginning MMT; 2) provider-initiated testing and counseling; 3) HIV Testing; and 4) HIV Testing result.

In addition, we also asked participants about their socio-demographic status (age, ethnicity, education, marital status, occupation), health status (any health problem in the last 30 days, $\mathrm{HBV}, \mathrm{HCV}$, opportunistic infections and Antiretroviral Therapy history), and their duration of using illicit drugs.

\section{Statistical analysis}

We analyzed data by using STATA software version 12.0 (StataCorp. LP, College Station, TX, USA). First, we described the frequency (n) and percentage occurrence (\%) of variables. To identify associated factors with good knowledge, levels of self-assessed HIV status and the HIV testing uptake among drug users, we used a multivariable logistic regression model. Potential associated factors with knowledge about HIV/AIDS included socio-demographic characteristics (age, ethnic, education, marital status, occupation), health problems in the last 30 days, currently enrolling in antiretroviral therapy and duration of drug use. Meanwhile, along with this pool of variables, we also tested the association between knowledge about HIV/AIDS and perceived HIV status and HIV testing uptake. A stepwise forward strategy including variables which have a $p$-value less than 0.1 was used as the reduced model to exclude variables with $\mathrm{p}$-value greater than 0.2 .

\section{Results}

A total of 300 participants enrolled in the study. The demographic characteristics of these patients are described in Table 1. All participants were male due to the centers that were chosen. Most participants were middle aged, with $36 \%$ being $30-39$ years old and $35.7 \%$ being 40-49. Kinh and Tay were the two most common ethnicities. The minority of participants $(8.7 \%)$ had an education level higher than high school. Most participants

Table 1 Demographic characteristics of respondents

\begin{tabular}{|c|c|c|}
\hline Characteristics & $n$ & $\%$ \\
\hline \multicolumn{3}{|l|}{ Age group } \\
\hline$<30$ & 51 & 17.0 \\
\hline $30-39$ & 108 & 36.0 \\
\hline $40-49$ & 107 & 35.7 \\
\hline$\geq 50$ & 34 & 11.3 \\
\hline \multicolumn{3}{|l|}{ Ethnicity } \\
\hline Kinh & 176 & 58.7 \\
\hline Tay & 14 & 4.7 \\
\hline Thai & 81 & 27.0 \\
\hline Others & 29 & 9.7 \\
\hline \multicolumn{3}{|l|}{ Education } \\
\hline$<$ High school & 168 & 56.2 \\
\hline High school & 105 & 35.1 \\
\hline$>$ High school & 26 & 8.7 \\
\hline \multicolumn{3}{|l|}{ Marital status } \\
\hline Single & 79 & 26.3 \\
\hline Live with spouse/partner & 177 & 59.0 \\
\hline Widow/Divorced & 44 & 14.7 \\
\hline \multicolumn{3}{|l|}{ Occupation } \\
\hline Unemployment & 24 & 8.0 \\
\hline Freelancer & 249 & 83.0 \\
\hline Worker/White-collar worker & 9 & 3.0 \\
\hline Others & 18 & 6.0 \\
\hline \multicolumn{3}{|c|}{ Having any health problem in the last 30 days } \\
\hline No & 266 & 88.7 \\
\hline Yes & 34 & 11.3 \\
\hline Antiretroviral therapy (ART) & 32 & 10.7 \\
\hline \multicolumn{3}{|l|}{ Duration of drug use } \\
\hline$<2$ years & 13 & 4.8 \\
\hline $2-5$ years & 79 & 29.3 \\
\hline $5-10$ years & 90 & 33.3 \\
\hline 10-20 years & 68 & 25.2 \\
\hline$>20$ years & 20 & 7.4 \\
\hline
\end{tabular}


were freelancers and lived with a spouse/partner. Very few had health problems in the last 30 days (11.3\%) and only $10.7 \%$ of all participants were receiving ART. Duration of drug use varied however most had used for more than 2 years.

Knowledge about HIV prevention and treatment among drug users is presented in Table 2. Almost all participants had heard of HIV. The majority (83.3\%) identified sharing needles and syringes as causing HIV transmission along with unsafe blood transfusions $(67.9 \%)$ and unprotected sex $(87.3 \%)$. More than half of the patients did not know that HIV could pass from mother to child. $94.7 \%$ identified that PWID were

Table 2 Knowledge about HIV prevention and treatment among drug users

\begin{tabular}{lll}
\hline Characteristics & $n$ & $\%$ \\
\hline Heard about HIV/AIDS & 3 & 1.0 \\
No & 297 & 99.0 \\
Yes & & \\
HIV/AIDS transmission & 203 & 67.9 \\
Blood Transfusion Unsafety & 249 & 83.3 \\
Sharing needles and syringes & 143 & 47.8 \\
Transmissible from mother to child & 261 & 87.3 \\
Unnprotected sex & & \\
Susceptibility to HIV infection & 283 & 94.7 \\
People who inject drugs & 229 & 76.9 \\
Sex workers & 18 & 6.0 \\
Long distance highway drivers & 89 & 29.9 \\
Multiple sex partners & 36 & 12.2 \\
Faithfulness to partners: a means to prevent HIV infection & \\
False & 360 & 87.8 \\
True & 260
\end{tabular}

The correct use of the condom reduces the risk of HIV infection

$\begin{array}{lll}\text { False } & 10 & 3.3 \\ \text { True } & 289 & 96.7\end{array}$

A healthy or healthy-looking person can be HIV-positive

$\begin{array}{lll}\text { False } & 69 & 23.2 \\ \text { True } & 229 & 76.9 \\ \text { Mosquitoes/insect can transmit HIV } & & \\ \text { False } & 40 & 13.4 \\ \text { True } & 258 & 86.6\end{array}$

HIV infection is transmitted through eating with a person with HIVinfected

\begin{tabular}{lll} 
False & 25 & 8.4 \\
True & 273 & 91.6 \\
Knowledge about HIV/AIDS & & \\
Not good & 117 & 39.7 \\
Good & 178 & 60.3 \\
\hline
\end{tabular}

susceptible to HIV. The majority thought that faithfulness to partners and correct condom use could prevent/ reduce HIV infection risk. Interestingly, the majority thought HIV could be spread by mosquitos (86.6\%) or by eating with an infected person (91.6\%). Despite this, $60.3 \%$ said their HIV knowledge was good.

Table 3 describes the attitudes about HIV prevention and treatment among drug users in Vietnam. Over a half of study participants reported that they were self-perceived as being at no risk of HIV (52.2\%) while $75.2 \%$ identified drug injecting as a reason for risk of HIV. The majority of participants identified not sharing needles $(66.7 \%)$ as a reason for no risk of HIV. Not having sex with female sex workers, using condoms and being faithful were other common reasons for no risk of HIV infection.

Patients' HIV testing histories are described in Table 4. Most patients (82.2\%) had availed of HIV testing and counselling services prior to MMT and for $60.2 \%$, this took place at provincial centers for HIV/AIDS prevention. $92.6 \%$ had had a HIV test and for $76.5 \%$ of these, the test was negative.

Table 5 examines factors associated to the knowledge, attitudes and practices of HIV prevention and treatment among male PWID. Knowledge of HIV was negatively associated with participants aged $30-39$, or those who were of Thai or other ethnic background compared to Kinh. The likelihood of knowing about HIV/AIDS was greater among those who were high school educated than those with less than high school. Although it was

Table 3 Attitudes about HIV prevention and treatment among drug users

\begin{tabular}{lll}
\hline Characteristics & $n$ & $\%$ \\
\hline Self-assessed HIV status & 143 & 52.2 \\
No risk & 67 & 24.5 \\
Low risk & 64 & 23.4 \\
High risk & & \\
Reasons for risk of HIV infection & 18 & 14.1 \\
Many partners & 17 & 13.3 \\
Sex without using condom & 97 & 75.2 \\
Drug-injection & 6 & 4.7 \\
Receiving blood transfusions & & \\
Reasons for no risk of HIV infection & 65 & 35.0 \\
Being faithful & 39 & 21.0 \\
Using condom & 124 & 66.7 \\
Not sharing needles & 11 & 5.9 \\
Not having friends with HIV infection & 18 & 9.7 \\
Not having anal sex & 53 & 28.5 \\
Not having sex with female sex workers & 7 & 3.8 \\
Not receiving blood transfusions & & \\
\hline
\end{tabular}


Table 4 Practices for HIV prevention and treatment among drug users

\begin{tabular}{lcc}
\hline Characteristics & $n$ & $\%$ \\
\hline Before beginning MMT, using HIV Testing and Counselling Services \\
No & 53 & 17.8 \\
Yes & 245 & 82.2 \\
Provider-initiated testing and counseling & & \\
Commune Health Stations & 24 & 12.9 \\
District health bureau & 39 & 21.0 \\
Provincial Center for HIV/AIDS Prevention & 112 & 60.2 \\
Others & 11 & 5.9 \\
HIV Testing & & \\
No & 22 & 7.4 \\
Yes & 276 & 92.6 \\
HIV Testing result & & \\
Positive & 48 & 17.4 \\
Negative & 211 & 76.5 \\
N/A & 17 & 6.2 \\
\hline
\end{tabular}

just "borderline" statistically significant, it is important to notice that patients who had 5-10 year of drug abuse were less likely to take HIV tests than those with less than 2 years drug use history.

\section{Discussion}

In this sample of male PWID prior to receiving MMT, we found that a large proportion of them had a good knowledge on the risks of HIV transmission. However, misconceptions about the forms of transmission were still seen as well as there being a lack of appreciation of the magnitude of unprotected sex for HIV transmission. Scaling up HIV testing and opioid dependence treatment services as well as expanding mass media campaigns are recommended in these disadvantaged settings.

This study contributes to the body of evidence on the HIV-related knowledge, attitudes and practices (KAP) for PWID commencing MMT in mountainous areas. This is important as PWID are at high risk of contracting HIV due to unsafe behaviors, especially in Vietnam where the HIV epidemic is concentrated among PWID. In addition, implementing interventions in disadvantaged settings are more challenging given the poor accessibility to respondents. By focusing on mountainous regions where MMT and HIV services are less prevalent, information can be gathered about how to enhance HIV prevention and minimize risk behavior. We found that misconceptions in some routes of HIV transmission still exist in this setting. Most patients knew that needle sharing leads to HIV transmission, however, mosquitoes and sharing food were also thought of modes of transmission. Most identified their knowledge of HIV as being good but also indicated that they had no risk of HIV. Before commencing MMT, 92.6\% had taken a HIV test with $17.4 \%$ being positive. Age, ethnicity and education level were identified as potentially being associated with knowledge of HIV/AIDS.

Overall, the level of 'good' knowledge about HIV/AIDS (60.3\%) was similar to other studies globally [24-26]. Most knew of the major modes of transmission, such as unsafe blood transfusions, unprotected sex and sharing needles and syringes, however only a minority knew that

Table 5 Associated factors related to knowledge, attitudes and practices of HIV prevention and treatment among drug users

\begin{tabular}{|c|c|c|c|c|c|c|}
\hline \multirow[t]{2}{*}{ Characteristics } & \multicolumn{2}{|c|}{ Knowledge on HIV/AIDS } & \multicolumn{2}{|c|}{ Perceived HIV status } & \multicolumn{2}{|c|}{ HIV Testing } \\
\hline & OR & $95 \% \mathrm{Cl}$ & OR & $95 \% \mathrm{Cl}$ & OR & $95 \% \mathrm{Cl}$ \\
\hline \multicolumn{7}{|l|}{ Age groups $(<30-$ ref $)$} \\
\hline $30-39$ & $0.39^{* * *}$ & $0.22 ; 0.69$ & & & & \\
\hline \multicolumn{7}{|l|}{ Ethnicity (Kinh - ref) } \\
\hline Tay & & & 0.43 & $0.12 ; 1.55$ & & \\
\hline Thai & $0.47^{* *}$ & $0.25 ; 0.87$ & & & 0.49 & $0.19 ; 1.30$ \\
\hline Others & $0.35^{* *}$ & $0.13 ; 0.93$ & & & & \\
\hline \multicolumn{7}{|l|}{ Education (<High school - ref) } \\
\hline High school & $2.76^{* * *}$ & $1.51 ; 5.05$ & & & & \\
\hline$>$ High school & 2.3 & $0.78 ; 6.76$ & & & & \\
\hline \multicolumn{7}{|l|}{ Occupation (Unemployment - ref) } \\
\hline Worker/ White-collar worker & & & 2.92 & $0.66 ; 12.91$ & & \\
\hline \multicolumn{7}{|c|}{ Duration of drugs use ( $<2$ years - ref) } \\
\hline $5-10$ years & & & & & $0.45^{*}$ & $0.18 ; 1.16$ \\
\hline$>20$ years & $0.41^{*}$ & $0.15 ; 1.14$ & 2.02 & $0.79 ; 5.20$ & & \\
\hline
\end{tabular}

${ }^{* *} p<0.01,{ }^{* *} p<0.05,{ }^{*} p<0.1 ;-$ ref Comparison group 
it could be passed from mother to child. Participants also identified that PWID and female sex workers were susceptible to HIV however only a third identified multiple sex partners as a risk. Faithfulness and condom use were known as methods of preventing transmission whereas, interestingly, most participants thought that mosquitoes and sharing food could transmit HIV. This result agreed with a similar study on knowledge of HIV in Iran, in which mosquitoes were identified as a vector of transmission [27]. In other studies, such as in Brazil and Cameroon, knowledge of transmission routes was significantly better, with only the minority in both cases reporting mosquitoes and food sharing as a mechanism for transmission [25, 26]. These differences in knowledge level may be attributed to the mountainous region in which this study was conducted. In other studies, urban and metropolitan areas were used. This could lead to a more educated sample, who had greater access to health service being chosen in the past. In Vietnam, there are differences in the level of educational services provided between provinces with the central, city regions having more higher-education opportunities [28]. In this study, the likelihood of good HIV/AIDS knowledge was higher among participants who were high school educated, demonstrating the impact that education can have for PWID. This agrees with international and Vietnamese data where education level and HIV knowledge are positively associated [29-31]. Increasing the access of PWID to further education could benefit their knowledge of HIV with an aim to decreasing the risk of transmission.

Smaller ethnic groups in mountainous areas were less likely to have good knowledge of HIV/AIDS compared to the majority group, Kinh. In other studies regarding health service utilization in mountainous areas of Vietnam, Kinh people were also shown to be the majority ethnic background utilizing services [32] despite minority groups being prevalent in these regions [33]. Malqvist et al. has suggested that discrimination in health service utilization still exists in Vietnam [34]. This finding indicates a cohort of PWID may have poor health service utilization and therefore need to be targeted to improve HIV knowledge. As ethnic groups are spread over a wide geographical, mountainous area, difficulty in getting to health service locations, both for MMT and HIV may be substantial and lead to decreased knowledge of HIV among these participants.

The majority of participants in our study identified that they were at no risk of HIV/AIDS, despite being PWID and having identified drug injection and PWID as being at higher risk. Reasons for this lack of risk varied however the most common was being faithful in sexual relationships, not sharing needles and not having sex with female sex workers. Only $21 \%$ reported to using condoms, a key practice in reducing the risk of HIV transmission [35]. Similar trends among PWID regarding HIV risks have been seen within Vietnam and globally [36-38] demonstrating the potentially risky behaviors that PWID are engaging in. While certain practices that they are engaging in, like not sharing needles should further be promoted, their attitudes to, for example using condoms, need to be altered to further decrease HIV risk. Changing attitudes among this group of PWID should help to change attitudes and practices among the hidden PWID population and therefore reduce HIV risk behavior.

Most participants had utilized HIV testing and counselling services and $92.6 \%$ had had a HIV test. Of these only $17.4 \%$ had a positive result. This is significantly lower than previous other studies in Vietnam which have placed the HIV rate among PWID at closer to $30 \%$ [32, 38, 39] indicating that, in the mountainous areas, HIV may be well controlled. It should also be acknowledged however that this study deals with a specific cohort of PWID who are actively seeking health care services are therefore may engage in safer practices. Most patients identified that they used provincial level centers for HIV services rather than commune level. This could be a barrier to HIV risk prevention as patients may not be able to attend provincial centers easily or frequently. A preference among MMT users for integrated and decentralized services has been suggest by Tran et al. [40] while people from mountainous regions living far from services are also less likely to use them [33]. Given the mountainous population being examined, long travel times to MMT and HIV services may be a deterrent. For PWID registering for MMT to improve their KAP of HIV and to prevent HIV transmission among this vulnerable group, integration of MMT and HIV services may be necessary. This may also assist in decreasing the hidden drug using population and increasing the number of people receiving comprehensive care.

This study is a baseline assessment of a longitudinal follow-up of MMT patients who were taking MMT in newly established clinics in mountainous areas of Vietnam. Therefore, it has several implications for designing comprehensive health services and interventions in this at-risk group. Firstly, mass media targeting of community and individual counseling services for naïve patients could be beneficial in reducing transmission and risk behaviors and promoting HIV services access, utilization and outcomes among PWID in mountainous areas. With integrated HIV and MMT services, including counselling services, attitudes and practices could be altered to not only reduce the risk of those receiving MMT but to also to those who remain hidden drug users. Moreover, increased services could help to access those who currently do not engage due to geographical barriers. 
This study has some limitations that should be acknowledged. This included the cross-sectional baseline design that limits the causal inference of KAP and HIV service uptake. In addition, the sample included only those accessing MMT services, and therefore, does not cover other at risk groups. This could introduce bias into the population selected as they may already have decreased risk behaviors as they engage freely with health services. Recall bias should also be considered a limitation of the study as data relied on participants self-reporting of drug use and HIV KAP. In addition, though being a rather reasonable choice given constraints of a study conducted in remote, under-developed area, the convenience sampling method adopted in this study may undermine the generalizability of our findings. Further studies on the topic with attempts to address these limitations, while also considering the inclusion of data on self-reported risk behaviors like injections and sexual behaviors, thus are being called for.

\section{Conclusions}

As there is a lack of data for mountainous regions in Vietnam regarding both MMT and HIV, this study sheds significant light on the knowledge and HIV services access among PWID in disadvantaged settings. This then could inform the design and development of services and intervention for this group.

\section{Abbreviations}

MMT: Methadone maintenance treatment; DALYs: Disability-Adjusted-Life Years; PWIDs: People who inject drugs

\section{Acknowledgements}

Not applicable.

Funding

There was no funding for this analysis.

\section{Availability of data and materials}

The data that support the findings of this study are available from Vietnam Authority of HIV/AIDS Control but restrictions apply to the availability of these data, which were used under license for the current study, and so are not publicly available. Data are however available from the authors upon reasonable request and with permission of Vietnam Authority of HIV/AIDS Control.

\section{Authors' contributions}

TMN, BXT, MF, MDP, LTN, ALTN, HTL, THN, VHH, XTTL, HLTN, HPD, PLD, HHN, $\mathrm{CL}, \mathrm{CSHH}, \mathrm{RCMH}$ conceived of the study, and participated in its design and implementation and wrote the manuscript. TMN, BXT, MF, MDP, LTN analyzed the data. TMN, BXT, MF helped to draft the manuscript. All authors read and approved the final manuscript.

\section{Ethics approval and consent to participate}

This study was reviewed and ethical approval was granted by the Research and Ethic Review Committee by the Vietnam Authority of HIV/AIDS Control, Ministry of Health of Vietnam. The research project has obtained written informed consent from all participants after clearly introducing the purpose the survey and the right of patients to refuse to participate or withdraw from the interview at any time, and this did not affect their continuation of health care services.

\section{Consent for publication}

Not applicable.

\section{Competing interests}

The authors declare that they have no competing interests.

\section{Publisher's Note}

Springer Nature remains neutral with regard to jurisdictional claims in published maps and institutional affiliations.

\section{Author details}

${ }^{1}$ Vietnam Authority of HIV/AIDS Control, Ministry of Health, Hanoi, Vietnam. ${ }^{2}$ Institute for Preventive Medicine and Public Health, Hanoi Medical University, Hanoi, Vietnam. ${ }^{3}$ Bloomberg School of Public Health, Johns Hopkins University, Baltimore, MD, USA. ${ }^{4}$ Vietnam Young Physician Association, Hanoi, Vietnam. ${ }^{5}$ University College Dublin, Belfield, Dublin, Ireland. ${ }^{6}$ National Institute of Hygiene and Epidemiology, Hanoi, Vietnam. ${ }^{7}$ Centre for Interdisciplinary Social Research, Phenikaa University, Hanoi, Vietnam. ${ }^{8}$ Université Libre de Bruxelles, B-1050 Brussels, Belgium. ${ }^{9}$ Institute of Philosophy, Vietnam Academy of Social Sciences, Hanoi, Vietnam. ${ }^{10}$ National Economics University, Hanoi, Vietnam. ${ }^{11}$ Sciences Po Paris, Campus de Dijon, 21000 Dijon, France. ${ }^{12}$ Department of Neurosurgery Spine-Surgery, Hanoi Medical University Hospital, Hanoi, Vietnam. ${ }^{13}$ Institute for Global Health Innovations, Duy Tan University, Da Nang, Vietnam. ${ }^{14}$ Center of Excellence in Evidence-based Medicine, Nguyen Tat Thanh University, Ho Chi Minh city, Vietnam. ${ }^{15}$ Department of Psychological Medicine, National University Hospital, Singapore, Singapore. ${ }^{16}$ Department of Psychological Medicine, Yong Loo Lin School of Medicine, National University of Singapore,

Singapore, Singapore. ${ }^{17}$ Center of Excellence in Behavioral Medicine, Nguyen Tat Thanh University, Ho Chi Minh City Singapore.

Received: 30 May 2018 Accepted: 3 January 2019

Published online: 15 January 2019

\section{References}

1. El-Bassel N, Shaw SA, Dasgupta A, Strathdee SA. Drug use as a driver of HIV risks: re-emerging and emerging issues. Curr Opin HIV AIDS. 2014;9(2):150-5.

2. Wang H, Wolock TM, Carter A, Nguyen G, Kyu HH, Gakidou E, Hay SI, Mills EJ, Trickey A, Msemburi W, et al. Estimates of global, regional, and national incidence, prevalence, and mortality of HIV, 1980-2015: the global burden of disease study 2015. The lancet HIV. 2016;3(8):e361-87.

3. Murray CJ, Ortblad KF, Guinovart C, Lim SS, Wolock TM, Roberts DA, Dansereau EA, Graetz N, Barber RM, Brown JC, et al. Global, regional, and national incidence and mortality for HIV, tuberculosis, and malaria during 1990-2013: a systematic analysis for the global burden of disease study 2013. Lancet. 2014;384(9947):1005-70.

4. Strathdee SA, Stockman JK. Epidemiology of HIV among injecting and noninjecting drug users: current trends and implications for interventions. Current HIV/AIDS reports. 2010;7(2):99-106.

5. Mathers BM, Degenhardt L, Phillips B, Wiessing L, Hickman M, Strathdee SA, Wodak A, Panda S, Tyndall M, Toufik A, et al. Global epidemiology of injecting drug use and HIV among people who inject drugs: a systematic review. Lancet. 2008:372(9651):1733-45.

6. Mathers BM, Degenhardt L, Bucello C, Lemon J, Wiessing L, Hickman M. Mortality among people who inject drugs: a systematic review and metaanalysis. Bulletin of the World Health Organisation. 2013;1(91):102-23.

7. National Drug Intelligence Center (NDIC): The Economic Impact of Illicit Drug Use on American Society. In.; 2011.

8. Mattick RP, Breen C, Kimber J, Davoli M. Methadone maintenance therapy versus no opioid replacement therapy for opioid dependence. Cochrane J Syst Rev. 2009;3.

9. Barnett P, Mattick RP, Breen C, Kimber J, Davoli M. Addiction. The costeffectiveness of methadone maintenance as a health careintervention. Addiction. 1999;94:479-88. https://doi.org/10.1046/j.1360-0443.1999.9444793. $x$

10. Wang PW, Wu HC, Yen CN, Yeh YC, Chung KS, Chang HC, Yen CF. Change in quality of life and its predictors in heroin users receiving methadone maintenance treatment in Taiwan: an 18-month follow-up study. Am J Drug Alcohol Abuse. 2012;38(3):213-9.

11. Xiao L, Wu Z, Luo W, Wei X. Quality of life of outpatients in methadone maintenance treatment clinics. J Acquir Immune Defic Syndr. 2010;53(Supp 1):S116. 
12. Baharom N, Hassan MR, Ali N, Shah SA. Improvement of quality of life following 6 months of methadone maintenance therapy in Malaysia. BMC substance Abuse Treatment, Prevention, and Policy. 2012;7(32).

13. Gowing L, Farrell M, Bornemann R, Sullivan LE, Ali R. Substitution treatment of injecting opioid users for prevention of HIV infection. Cochrane Database Syst Rev. 2008:2.

14. Karki P, Shrestha R, Huedo-Medina TB, Copenhaver M: The impact of methadone maintenance treatment on HIV risk behaviors among high-risk injection drug users: a systematic review. Evidence Based Med Public Health 2016, 2:e:1229.

15. Wang M, Mao W, Zhang L, Jiang B, Xiao Y, Jia Y, Wu P, Cassell H. S. V: methadone maintenance therapy and HIV counseling and testing are associated with lower frequency of risky behaviors among injection drug users in China. Subst Use Misuse. 2015;50(1):15-23.

16. Nguyen TTM, Nguyen LT, Pham MD, Hoang HV, Mulvey KP. Methadone maintenance therapy in Vietnam: an overview and scaling-up plan. Adv Prev Med. 2012;2012.

17. Ministry of Health: Vietnam National Response to HIV/AIDS Report. In. Hanoi; 2016.

18. Kato M, Long NH, Duong BD, Nhan DT, Nguyen TTV, Hai N, Giang LM, Hoa DM, Van NT, Suthar A, et al. Enhancing the benefits of antiretroviral therapy in Vietnam: towards ending AIDS. Current HIV/AIDS Report. 2014;11:487-95.

19. Viet Nam Authority of HIV/AIDS Control: An annual update on the HIV epidemic in Viet Nam. In. Hanoi: National Institute of Hygiene and Epidemiology (NIHE; 2014.

20. Ministry of Health: HIV/STI Integrated Biological and Behavioral Surveillance (IBBS) in Vietnam: round III. In. Hanoi; 2014.

21. Tran BX, Ohinmaa A, Duong AT, Do NT, Nguyen LT, Nguyen QC, Mills S, Jacobs $P$, Houston $S$. Changes in drug use are associated with healthrelated quality of life improvements among methadone maintenance patients with HIV/AIDS. Qual Life Res. 2012;21(4):613-23.

22. Vuong T, Shanahan M, Nguyen N, Le G, Ali R, Pham K, Vuong T, Dinh T. A $R$ : cost-effectiveness of center-based compulsory rehabilitation compared to community-based voluntary methadone maintenance treatment in Hai Phong City, Vietnam. Drug and Alcohol Dependency. 2016;168:147-55.

23. Tran BX, Phan HT, Nguyen LH, Nguyen CT, Nguyen AT, Le TN, Latkin CA. Economic vulnerability of methadone maintenance patients: implications for policies on co-payment services. Int J Drug Policy. 2016;31:131-7.

24. Hong SY, Thompson D, Wanke C, Omosa G, Jordan MR, Tang AM, Patta S, Mwero B, Mjomba I, Mwamburi M. Knowledge of HIV transmission and associated factors among HIV-positive and HIV-negative patients in rural Kenya. J AIDS Clin Res. 2012;3(7).

25. Nubed CK, J-FTK A. Knowledge, attitudes and practices regarding HIV/AIDS among senior secondary school students in Fako division, south west region, Cameroon. BMC Public Health. 2016;16(1):847.

26. Bertoni N, Singer M, Silva CM, Clair S, Malta M, Bastos FI. Knowledge of AIDS and HIV transmission among drug users in Rio de Janeiro, Brazil. BMC Harm Reduction J. 2011;8(5).

27. Shokoohi M, Karamouzian M, Mirzazadeh A, Haghdoost A, Rafiera A-A, Sedaghat A, Sharifi H. HIV knowledge, attitudes, and practices of young people in Iran: findings of a National Population-Based Survey in 2013. PLoS One. 2016;11(9):e0161849.

28. World Bank Group: Education in Vletnam: Development History, Challenges and Soluntions. In. Hanoi; 2006.

29. Mwamwenda TS. Education level and human immunodeficiency virus (HIV)/ acquired immune deficiency syndrome (AIDS) knowledge in Kenya. J AIDS and HIV Res. 2014;6(2):28-32.

30. Hoang D, Dinh AT, Groce N, Sullivan LE. Knowledge and perceptions of HIVinfected patients regarding HIV transmission and treatment in Ho Chi Minh City, Vietnam. Asian Pacific Journal of Public Health. 2015;27(2):NP746-57.

31. Sheikh MT, Uddin MN, Khan JR. A comprehensive analysis of trends and determinants of HIV/AIDS knowledge among the Bangladeshi women based on Bangladesh demographic and health surveys, 2007-2014. Archives of Public Health. 2017:75(59)

32. Nguyen LH, Nguyen LHT, Boggiano VL, Hoang CD, Nguyen HV, Le HT, Le HQ, Tran TD, Tran BX, Latkin CA, et al. Quality of life and healthcare service utilization among methadone maintenance patients in a mountainous area of northern Vietnam. Health Qual Life Outcomes. 2017;15(77).

33. Toan NV, Trong LN, Höjer B, LA P. Public health services use in a mountainous area, Vietnam: implications for health for policy. Scandinavian J Public Health. 2002;30(2):86-93.
34. Malqvist M, Hoa DT, Liem NT, Thorson A. S T: ethnic minority health in Vietnam: a review exposing horizontal inequity. Glob Health Action. 2013;6:1-19.

35. Varghese B, Maher J, Peterman T, Branson B, Steketee R. Reducing the risk of sexual HIV transmission: quantifying the per-act risk for HIV on the basis of choice of partner, sex act, and condom use. Sexual Trans Dis. 2002;29(1): 38-43.

36. Mishra RK, Ganju D, Ramesh S, Lalmuanpuii M, Biangtung L, Humtsoe C, Saggurti N. HIV risk behaviors of male injecting drug users and associated non-condom use with regular female sexual partners in north-East India. Harm Reduct J. 2014;11:5.

37. Broz D, Wejnert C, Pham HT, DiNenno E, Heffelfinger JD, Cribbin M, Krishna $\mathrm{N}$, Teshale EH, P-B G. HIV infection and risk, prevention, and testing behaviors among injecting drug users - national HIV behavioral surveillance system, 20 U.S. cities. MMWR Surveilance Summary 2014. 2009;63(6):1-51.

38. Do K, Minichiello V, Hussain R. HIV risks among injecting drug users in Vietnam: a review of the research evidence. Curr HIV Res. 2012;10(6):479-86.

39. Tran TMT, Nguyen HT, Yatsuya H, Hamajima N, Nishimura A, Ito K. HIV prevalence and factors associated with HIV infection among male injection drug users under 30: a cross-sectional study in Long an, Vietnam. BMC Public Health. 2006:6(248).

40. Tran BX, Nguyen LH, Phan HT, Nguyen LK, Latkin CA. Preference of methadone maintenance patients for the integrative and decentralized service delivery models in Vietnam. Harm Reduct J. 2015;12(29).
Ready to submit your research? Choose BMC and benefit from:

- fast, convenient online submission

- thorough peer review by experienced researchers in your field

- rapid publication on acceptance

- support for research data, including large and complex data types

- gold Open Access which fosters wider collaboration and increased citations

- maximum visibility for your research: over $100 \mathrm{M}$ website views per year

At $\mathrm{BMC}$, research is always in progress.

Learn more biomedcentral.com/submissions 